Article

\title{
Awareness and Benefits of Self-Curing Concrete in Construction Projects: Builders and Civil Engineers Perceptions
}

\author{
David O. Nduka ${ }^{1, *}$, John O. Ameh ${ }^{2}$, Opeyemi Joshua ${ }^{1}$ and Rapheal Ojelabi ${ }^{1}$ \\ 1 Department of Building Technology, Covenant University, Ota 112233, Nigeria; \\ opeyemi.joshua@covenantuniversity.edu.ng (O.J.); rapheal.ojelabi@covenantuniversity.edu.ng (R.O.) \\ 2 Department of Building, University of Lagos, Akoka 100213, Nigeria; oameh@unilag.edu.ng \\ * Correspondence: david.nduka@covenantuniversity.edu.ng; Tel.: +234-806-668-0238
}

Received: 28 June 2018; Accepted: 6 August 2018; Published: 14 August 2018

\begin{abstract}
Self-cured concrete is a type of concrete with a special ability to reduce autogenous shrinkage responsible for early-stage cracking. It is useful generally for the construction of high rise buildings and bridges. The application and use of this technique of curing concrete, however, depends on the level of awareness among stakeholders regarding the application of the technique and its benefits among other factors. This study, therefore, sets out to investigate the level of awareness of selected construction professionals regarding the self-curing concrete technique in addition to the benefits. A cross-sectional survey design method was embraced by giving out 115 questionnaires to builders and engineers in Lagos who were purposely selected. The data was subjected to descriptive statistics. The results indicate that about $21 \%$ of selected builders and civil engineers practicing in Lagos are not aware and familiar with the concept of self-curing technology while about $43.1 \%$ of the professionals who have the knowledge of SCT have never used it in their professional practice. In addition, lower permeability, reduced coefficients of thermal expansion, and improved microstructures of cementitious paste were perceived as the dominant benefits of the self-curing concrete method. The implication of this study to construction professionals in Nigeria is in developing capacities on innovation practices in high-strength concrete technologies that will make them strike a balance with international counterparts.
\end{abstract}

Keywords: high performance concrete; high-strength concrete; internal curing; self-curing

\section{Introduction}

There have been rapid advancements in concrete technology within the last two decades aimed at improving the engineering properties of concrete. One such advancement is in the pursuit of high performance concrete (HPC) and high-strength concrete (HSC), which has found application in the construction of tall buildings, precast pylons, tunnels, shotcrete repairs, bridges, and more [1]. HPC and HSC are terms that described a low water-to-binder ratio (0.2-0.45) concrete that fulfills special requirements in terms of performance and durability [2]. However, Power's model specifies a water-to-binder ratio of 0.36 as the highest amount of water for internal curing water in HPC while noting that complete hydration is feasible in the $\mathrm{w} / \mathrm{c}$ range between $0.36-0.42$ if the $\mathrm{w} / \mathrm{c}+\mathrm{w}_{\text {ic }} / \mathrm{c}=0.42$ [3].

Previous studies have reported that HPC provides increased strength, higher stiffness, higher durability, reduced creep, economical cost, and effective impact resistance. In achieving the desired quality in HPC, various mineral materials such as fly ash, silica fume, and superplasticizers are added [4]. However, the problem of early age cracking is a major impediment to HPC. Causes of early age cracking as noted by Mousa et al. [5] are thermal effects, autogenous stresses, strains, 
and drying. Among the factors listed, researchers are of the opinion that autogenous shrinkage called self-desiccation is the main cause of early-stage cracking that occurs during the hydration period.

There is usually an insufficient water supply for proper hydration in HPC as a result of a low water-to-cement ratio and the presence of additive such as silica fume [6]. Additionally, difficulty with curing of vertical members using the traditional curing approach, inaccessibility to certain locations in buildings for curing purposes, and poor workmanship calls for a paradigm shift in curing technology. Innovative concrete curing technology, which is gaining popularity within the practice and research community is called self-curing technology (SCT) or Internal Curing (IC). These terms are used to define concrete with increased water retention capacity during the curing regime as opined by El-Dieb [7]. Justs et al. [8] defines self-curing concrete as "the process by which small inclusions dispersed within the concrete hold the water during mixing and up to the setting time and release it during cement hydration." The practice of self-curing is a likely method that can provide more water to concrete for more effective hydration of cement and reduced self-desiccation. Studies have identified various methods aimed at achieving internal-curing in construction projects. For instance, Madduru et al. [9] and Krishna and Jaipal [10] grouped materials used for achieving self-curing concrete into four: light weight aggregate, superabsorbent polymers (SAP), shrinkage reducing admixtures, and wood powder. Light weight aggregates include natural and synthetic expanded shale, light weight sand with water absorption rate of $17 \%$, and a $19 \mathrm{~mm}$ lightweight aggregate with water absorption rate of $20 \%$. Superabsorbent polymers also known as hydrophilic chemicals include polyvalent alcohol, polyethylene glycol (PEG), poly-acrylic acid, xylitol, sorbitol, glycerine, phytosterols, hyaluronic, polyxyelhylene (POE), sodium pyrrolidone carboxylate (PCA-na), stearyl alcohol, cetyl alcohol, thermosetting polymer, and urethanes. Two major schemes include the saturated light weight aggregate and superabsorbent polymers that have been established in research studies $[4,5,11]$ as the most effective means of actualizing internal curing.

Notable benefits of this practice include increased hydration and strength process, reduced autogenous shrinkage and cracking, reduced permeability, and increased durability [12,13]. Accordingly, the effective curing method initiated and accomplished during concrete mixing will be a viable option to meet the shortfall of traditional curing techniques.

Among concrete technology research studies, several studies have indicated that internal curing has significant effects on concrete performance. Noted in this direction is the experimental study of El-Dieb [7] that investigated the water retention capability, hydration, and moisture transportation in self-curing concrete containing different doses of polyethylene glycol. His findings reveal high water retention, less desiccation, and better hydrated concrete resulting in better mechanical properties and durability. In the same vein, the study from Justs et al. [8] aimed at limiting self-desiccation and autogenous shrinkage in ultra-high performance concrete, which shows effectiveness in reducing internal relative humidity. Olawuyi and Boshoff [14] investigate the inclusion of SAP as a curing agent at different curing regimes of air void distribution using the micro-CT analyzer in South Africa. Their study inferred additional internal water availability resulting in increased cement hydration products. Youssef [15], Afifi [16], and Rahman [17] demonstrated internal curing in the cementitious system using a saturated light weight aggregate, recycled aggregates, and brick chips, respectively. The findings of the authors show similar results in providing better mechanical properties, durability, and reduced autogenous shrinkage when incorporating light weight aggregates as a curing agent.

In Nigeria, there have been several published works on conventional curing methods of normal strength concrete. For instance, Akinwumi and Gbadamosi [18] determined the effects of curing methods (e.g., covering with wet rug plastic and air-curing methods) in determining the compressive strength of normal strength concrete in a tropical region. The findings revealed a greater strength when it comes to ponding with lime water. Similarly, Abalaka and Okoli [19] and Olanade, Fitriani, and Kola [20] compared the mechanical properties of normal strength concrete cured by immersion in water and air. Their studies revealed a direct correlation between the compressive strength and curing regime. From the discussions, there seems to be a lack of studies addressing construction professional's 
awareness and benefits of internal curing techniques from both developed and developing countries. This study becomes necessary since the application of this type of concrete curing depends on the level of awareness of stakeholders regarding the application of the technique and the benefits among other factors. This gap in literature will be addressed in the present study. The aim of this study, therefore, is to investigate the awareness and benefits associated with the self-curing method in high performance concrete in Nigeria. Objectives of the study are to ascertain the level of awareness and appraise the benefits derived from the implementation of the self-curing technique. This study is important since it provides current literature on the awareness and benefits regarding the implementation of SCT. It will also provide insight to both government, statutory bodies, and private sectors on likely causes of poor performance of HPC in Nigeria. This will increase the future performance of HPC projects and the state of knowledge of self-curing techniques in the country and other developing country constructing high-rise buildings and bridges.

\section{Review of Literature}

\subsection{Concept of Internal Curing/Self-Curing}

It is widely acknowledged that, amongst researchers and practitioners, internal curing concepts emerged from the United States by Paul Klieger in 1957 [2,17,21,22]. However, the concept of internal curing is new in concrete design while porous light weight aggregates (LWAs) have been used in improving the hydration of cement paste in the late 1950s. It is reported that deliberate research attempts on the use of LWAs for internal curing began by a group of researchers in Europe [17,21,22]. These advances stimulated both the spatial distribution and the amount of saturated LWAs to be mixed in a concrete. However, the optimization of internal curing at limiting shrinkage was substantially influenced by the type of cement used in the concrete. Therefore, conventional curing may be inoperative in preventing self-desiccation at the middle of the dense concrete element but creates unfavorable ambient conditions.

\subsection{Materials Used for Internal Curing (IC)/Self-Curing Techniques (SCT)}

The materials used as IC/SCT agents are discussed under the following sub-sections.

\subsection{Pre-Wetted Light Weight Aggregate}

Pre-wetted LWAs aggregates (LWAs) have been adjudged to be the first material used in IC technology as pioneered by Klieger in 1957 [21,22]. These materials have the capacity to absorb a considerable amount of water during mixing and subsequently discharge the fluid to the cement paste during the hydration process. Natural occurring and synthetic aggregates are two groups of aggregates identified to possess water retention qualities. Synthetic aggregates are shale and clay, pumice, perlite, and air-cooled blast furnace $[5,10]$. Recent studies have investigated the effects of LWAs in determining the properties of self-cured concrete. Towards this end, Yousef [15], Afifi [16], Rahman [17], Bashandy et al. [4], and Revalthy and Lakasini [23] incorporated LWAs in cementitious material in determining the effects of the material on the internally cured specimen. These studies revealed a significant reduced autogenous shrinkage and improvement in mechanical properties of the product.

\subsection{Super Absorbent Polymers}

Superabsorbent polymers (SAP) are "cross-linked polyelectrolytes which start to swell upon contact with water resulting in the formation of a hydrogel" $[23,24]$. SAP came in existence in the late 1980s and are primarily utilized in diapers [2,22]. It's incorporation in HPC is said to be due to the ability to absorb a large amount of water many times of its own weight, retain it, and release it when the internal or external environment changes. SAP can deliver internal water evenly through the area of an element and enhance the scale of reaction of the cement and other supplementary 
cementitious materials (SCMs). Self-desiccation of HPC at an early age are reduced by the addition of SAP, which was reported in the studies of Mousa et al. [5], Justs et al. [8], Olawuyi [2], Maddura et al. [9], and Mehdipour and Khayat [24]. Therefore, studies on the cracking possibility of HPC internally cured with SAP at an initial stage are more in contemporary concrete literatures.

\subsection{Awareness and Benefits and of Internal Curing}

Awareness, formal knowledge, and understanding the benefits of self-cured concrete by construction professionals remain essential mechanisms for improving the quality of concrete product and skills and promoting sustainable construction. Self-curing of HPC is increasing in popularity and has been adopted globally for tall building and other infrastructure developments. Undoubtedly, awareness precedes knowledge and helps people identify why a particular problem is needed and the requirements to achieve the task. Benefits of SCT in high performance concrete has been reported by several authors as useful means of mitigating autogenous shrinkage and chloride penetration reduction in concrete $[13,24,25]$. The internal curing agent provides an avenue for further cement hydration through the absorption of water before or during the mixing of concrete. The absorbed water gradually dissipates during the concrete hardening process, which resulted in providing extra water that may have been lost due to external environmental influences. Notable benefits of internal curing as posit by Shen et al. [25] are reduced autogenous shrinkage, crack-free microstructure, and increased durability of a concrete product. However, the mechanical properties of internally cured cementious products are reported to be affected by voids creation $[13,14]$.

Some of the identified benefits of IC are briefly discussed below.

\section{- Lower Permeability and Evaporation}

The deterioration of concrete exposed to environmental elements is linked to its permeability. A well-designed concrete is deemed to be water tight and has discontinuous pores and microstructure. Conversely, when concrete is subjected to severe loading and weathering, the physical and chemical process of deterioration like cracking begins to manifest [26]. The prolonged permeability as a result of cracking permits more water and other hostile attacking chemicals like chloride, Sulphur, and carbonate to infiltrate into concrete, which further deteriorates concrete. In addressing this problem, Mousa et al. [27] incorporated saturated Leca LWA at 20\% replacement of sand as an internal curing agent in achieving lower permeability in self-cured HPC. Additionally, Kamal et al. [28] investigated the behavior of normal strength and high strength self-curing and self-compacting concrete induced with a SAP curing agent. Results shown that mutually normal strength and high strength self-curing and self-compacting concrete exhibit an appreciable water retention capacity, which results in reduced evaporation and adequate hardened concrete properties.

\section{- $\quad$ Reduced Coefficient of Thermal Expansion (CTE)}

Wyrzykowski and Lura [29] define the coefficient of thermal expansion (CTE) "as both the contraction and expansion potential of a material, which is generally found to be symmetrical for temperature steps encountered in practice." The significance of the coefficient of thermal expansion of cement paste stems from the need to determine the internal stresses among various stages in cement-based material and to envisage the likely damage brought by the disparity of thermal dilation of each stage [30]. They noted the CTE value for hardened cement paste to be about $15-20 \times 10^{-6} /{ }^{\circ} \mathrm{C}$. Wyrzykowski and Lura [29] experimentally studied thermal expansion using volumetric and linear methods of a series of cement paste and mortars of different water-to-cement ratios. Their study showed that superabsorbent polymers (SAP) practically eliminates the increase in coefficient of thermal expansion throughout the initial days of hardening. They related the reduction of CTE to high internal relative humidity of the investigated sample. 


\section{- Improved Interfacial Transition Zone (ITZ)}

The interfacial transition zone (ITZ) between mineral aggregates is largely recognized as the weaker region within a concrete matrix. Jixiu et al. [31] note that, at inception of hydration, the region nearest to the aggregate has average, less cement strains and is normally filled with water and pores. They also pointed out that concrete usually experiences stress concentration at the interfacial transition zone owing to different elastic ratios between aggregate and bulk cement paste resulting to micro cracks and macro cracks in concrete on load application. Similarly, Sun et al. [32] found that concrete structure has more pores and micro-cracks than buck paste at the ITZ region through SEM imaging, transport simulation, and hydration modelling analyses. Moreover, Jixiu et al. [31] also experimentally found that mineral additives included in HPC are effective in improving strength at the interfacial transition zone. Likewise, in determining the suitability of IC in improving heat cured concrete, Nie et al. [33] found that IC substantially improved both the ITZ as well as the microstructure with less porosity.

\section{- Cement Hydration and Microstructure of Cementitious Paste}

Cement hydration proceeds when dry cement mixed with water results with a simultaneous and successive amount of exothermic chemical reactions. This reaction leads to the formation of new silicate and aluminate hydrated phases, which start to precipitate from the solution of the existing grains furthering the dissolution of the anhydrous phase through different processes [34]. Kang et al. [26] assert that the addition of the internal curing agent like SAP in HPC increase the rate of hydration in cementitious matrix. In an attempt to investigate hydration processes in HPC, Kim and Lee [35] studied the hydration kinetics of high-strength concrete with bottom ash as an internal curing agent. Their result showed the propensity of hydration improvement with bottom ash as an internal curing agent. Furthermore, unstructured calcium silicate hydrate (C-S-H) also known as the hydrated phase has been noted in literature to be responsible for binding features of cement that contains a great surface area and characteristics of a stiff gel $[34,35]$. Ridi, et al. [34] conclude that the inclusion of SAP in HPC contributes to the densification of the microstructure of high performance concrete. They also experimentally found that the internal curing method is linked to improved strength, an improved degree of the hydration process, and penetration resistance of heat cured concrete as well as an improved microstructure with a lower porosity in HPC.

\section{- Increased Strength and Good Impact Resistance}

Compressive strength of concrete is usually related to the curing age at a specified temperature and relative humidity. One of the key factors that promotes high compressive strength in HPC is the compact nature of raw materials, which are attainable by low w/c ratio and the equally filled small grains [35]. The Kevern and Nowasell [36] study on internal curing of pervious concrete using light weight aggregates revealed improved strength, a high degree of hydration, less shrinkage, and free-thaw over the control mixture. Additionally, Olawuyi and Boshoff [37] inferred that the addition of SAP as an internal curing agent gave a compressive strength that is commensurate to the expectation of the design mix to the limit of SAP addition as investigated. In another study by Pickel, et al. [38] on assessing the benefits of a pre-socked recycled concrete aggregate on internally cured concrete. Their results revealed that saturated high absorption recycled the concrete aggregate and appeared to provide some benefits in terms of compressive strength.

\section{- $\quad$ Tensile Creep}

Tensile creep is fundamental for calculating the cracking possibility of HPC precisely and is important for durability of concrete in event of controlled shrinkage at an initial stage. The outcomes of tensile creep can be realized to be comparatively great and substantial in the advance of self-induced stress. Shen et al. [25] investigated the influence of internal curing using SAP on the tensile creep at an 
early age. Their results showed a decreased tensile creep and autogenous shrinkage with an increase in the SAP amount.

\section{- Autogenous Shrinkage}

Concrete contracts due to moisture escape to the environment or through self-desiccation. The resultant effect of contraction in concrete is usually the tensile stress, which occurs to the element as a result of restraints from adjoined members [39]. The stress possibly will surpass the tensile strength and may trigger concrete to crack. In many cases, environmental humidity is lower than the humidity inside of concrete, which prompts the water in concrete to evaporate and causes shrinkage in concrete [40]. This type of shrinkage is synonymous with drying shrinkage. Another means of initiating moisture loss in concrete is through cement hydration, which is called self-desiccation or autogenous shrinkage. Utilization of a pre-soaked aggregate and SAP as an internal tank to provide water to concrete experiencing drying are effective approaches to reduce the shrinkage of concrete [38]. Maruyama and Teramoto [41] investigated the effects of water-restraining LWAs on the thermal expansion coefficient in mortar subject to temperature histories. They found that addition of water-saturated LWA with a ground granulated blast furnace slag was valid for reduced autogenous shrinkage and coefficient thermal expansion. Similarly, the Kang et al. [26] study experimentally demonstrated that shrinkage in HPC is well solved by implementing a SAP-centered internal curing procedure.

\section{Research Methodology}

This part outlines the methods used in achieving the specific objectives of this study.

To accomplish this study, a blend of literature review and administration of a closed-ended questionnaire were used. The research studies aid in identifying variables used in the research instrument. The study utilizes an exploratory design so that constructs and concepts will be generated and can be further subjected to validation in future studies [42]. The research design was motivated for its quantitative features and also no study has been conducted profiling construction professionals' perspectives on self-curing concrete. A cross sectional survey was adopted so that findings of the results can be generalized and reliable due to the collection of data from large samples [43]. The instrument was externally validated by peer review.

The survey instrument was administered by hand to builders and civil engineers during their monthly professional meetings, respectively. Builders and civil engineers were selected based on their related experiences in building production management and structural design of buildings and infrastructural projects, respectively. Builders are academically trained and statutory registered professionals responsible for building production management in Nigeria while civil engineers (structure) are experts in structural design of construction projects. The study purposively distributed 250 questionnaires to selected respondents. The sampling technique was selected because the respondents are knowledgeable and experienced in the field of building production management and concrete design. The sample frame consists of 115 valid questionnaires from 66 builders and 49 civil engineers. Descriptive statistics like frequencies, tables, figures, and means were used to analyze data obtained from the questionnaires.

The survey instrument consists of three Parts. Part (A) seeks to understand the personal profile of the respondents and their organization. Information on part (A) are required to moderate the core parts $(B)$ and $(C)$. In part $B$, the respondents were required to ascertain the level of awareness of self-curing concrete using six structured questions. Question one asked about the first source by which self-curing was learned. The corresponding options included: "personal research", "media/articles", "professional practice", "workshops/seminars" and "Internet". Question two sought to know the he time respondents first heard of the term "self-curing concrete" with options: "in the last one month", "in the last 12 months", "in the last three years", "more than three years ago" and "I have not heard about it". Question three inquires the last time self-curing technique was used by respondents in curing concrete with multiple answers: "one month ago", "last six months", "last 12 months", "more 
than 12 months ago" and "never". Respondents who have used SCT were required to indicate the effectiveness of self-curing in providing internal moisture by responding to multiple options "extremely effective", "very effective", "somewhat effective", "not so effective", "much less effective" and "no idea". Furthermore, the respondents who have identified the effectiveness were required to indicate the likelihood of specifying and implementing self-cured concrete in HPC using the following options: "much more likely", "more likely", "likely", "less likely" and "not at all". Lastly, the respondents who have used and known the effectiveness of self-curing were required to indicate the curing practice they are likely to adopt in HPC by choosing one of multiple options, which includes: "immersion", "sprinkling/spraying", "covering with burlap sack/membrane" and "self-curing".

In Part C, the respondents with knowledge and effectiveness of SCT were required to rate 10 identified benefits that drive self-curing techniques by responding on a 5 Likert scale 1-5. $1=$ "not beneficial," $2=$ "slightly beneficial," 3 = "moderately beneficial," 4 = "beneficial," and $5=$ "highly beneficial."

\section{Results and Discussion}

\subsection{Organizational Details and Personal Data of Respondents}

The study sought to know the details of the respondents' organization and personal data. This is presented in Table 1 . The analysis shows that $62.6 \%$ are in a contracting organization, $13.9 \%$ are in a consulting firm, $13.0 \%$ are in a client organization, and $10.4 \%$ are in academia. Only $19.1 \%$ of the respondents work in large organizations with more than 250 employees, $23.5 \%$ work in medium-sized organizations with employees ranging from 51-249, and 57.4\% work in small-sized organizations with less than 50 employees. Respondents in an indigenous organization represent $88.7 \%$ while $11.3 \%$ represents respondents working with multinational organizations. Only $0.9 \%$ have 41 or more years' of experience in construction, $8.7 \%$ have $21-30$ years of experience, $13.9 \%$ have $31-40$ years' of experience while those with 11-20 years' of experience had the highest response rate of $41.7 \%$. This suggests that the respondents have reasonable understanding in construction jobs and, therefore, information on self-curing obtained from them will be reliable. The profile of the respondents shows that $1.7 \%$ obtained OND, 6.3\% obtained PhD, 8.7\% held PGD, 18.3\% held MSc/MBA, 32.2\% held HND, and the $33.0 \%$ of the respondents obtained BSc/BTECH. In terms of professional affiliation, $57.4 \%$ are affiliated with the Council of Registered Builders of Nigeria while $42.6 \%$ are affiliated with the Council for the Regulation of Engineering in Nigeria. In terms of the membership grade, $1.7 \%$ are in the fellow category, $14.8 \%$ are in the probationer category, $23.5 \%$ are graduate members, and $60 \%$ are corporate members of their various professional bodies.

Table 1. Respondents' organization details and personal data.

\begin{tabular}{lcc}
\hline Personal Data Characteristics & Frequency (N) & Percentage (\%) \\
\hline Types of Organization & & \\
Consulting & 16 & 13.9 \\
Contracting & 72 & 62.6 \\
Client organization & 15 & 13.0 \\
$\quad$ Academia & 12 & 10.4 \\
Total & $\mathbf{1 1 5}$ & $\mathbf{1 0 0}$ \\
\hline Size of Organization & & \\
Small & 66 & 57.4 \\
Medium & 27 & 23.5 \\
$\quad$ Large & 22 & 19.1 \\
Total & $\mathbf{1 1 5}$ & $\mathbf{1 0 0}$ \\
\hline Ownership Status of Organization & & \\
$\quad$ Indigenous & 102 & 88.7 \\
$\quad$ Multinational & 13 & 11.3 \\
Total & $\mathbf{1 1 5}$ & $\mathbf{1 0 0}$ \\
\hline
\end{tabular}


Table 1. Cont.

\begin{tabular}{|c|c|c|}
\hline Personal Data Characteristics & Frequency (N) & Percentage $(\%)$ \\
\hline \multicolumn{3}{|l|}{ Years of Working Experience } \\
\hline $1-10$ & 39 & 33.9 \\
\hline $11-20$ & 48 & 41.7 \\
\hline $21-30$ & 10 & 8.7 \\
\hline $31-40$ & 16 & 13.9 \\
\hline $41-50$ & 1 & 0.9 \\
\hline 51 and above & 1 & 0.9 \\
\hline Total & 115 & 100 \\
\hline \multicolumn{3}{|l|}{ Academic Qualification } \\
\hline OND & 2 & 1.7 \\
\hline HND & 37 & 32.2 \\
\hline $\mathrm{BSc} / \mathrm{BTECH}$ & 38 & 33 \\
\hline PGD & 10 & 8.7 \\
\hline MSc/MBA & 21 & 18.3 \\
\hline Ph.D. & 7 & 6.3 \\
\hline Total & 115 & 100 \\
\hline \multicolumn{3}{|l|}{ Profession Background } \\
\hline Building & 66 & 57.4 \\
\hline Civil Engineering & 49 & 42.6 \\
\hline Total & 115 & 100 \\
\hline \multicolumn{3}{|l|}{ Affiliated Professional Body } \\
\hline CORBON & 66 & 57.4 \\
\hline COREN & 49 & 42.6 \\
\hline Total & 100 & 100 \\
\hline \multicolumn{3}{|l|}{ Grade of Membership } \\
\hline Probationer & 17 & 14.8 \\
\hline Graduate & 27 & 23.5 \\
\hline Corporate & 69 & 60.0 \\
\hline Fellow & 2 & 1.7 \\
\hline Total & 115 & 100 \\
\hline
\end{tabular}

\subsection{Awareness Level of Self-Curing Concrete}

\subsubsection{First Source by Which Self-Curing Was Learned}

The study investigated the first information source and platform by which the self-curing technique was learned. The result presented in Figure 1 shows that $45.2 \%$ of respondents learned about the self-curing method during the course of their professional practice, $13.0 \%$ learned through personal research, $12.2 \%$ through the Internet, $10.4 \%$ never learned SCT from any source, and $9.6 \%$ learned it through media/article and workshops/seminars, respectively. These results are not surprising since professional practice options reveal the highest learning source of SCT. This is because the practice of internal curing may only be seen during the construction phase. 


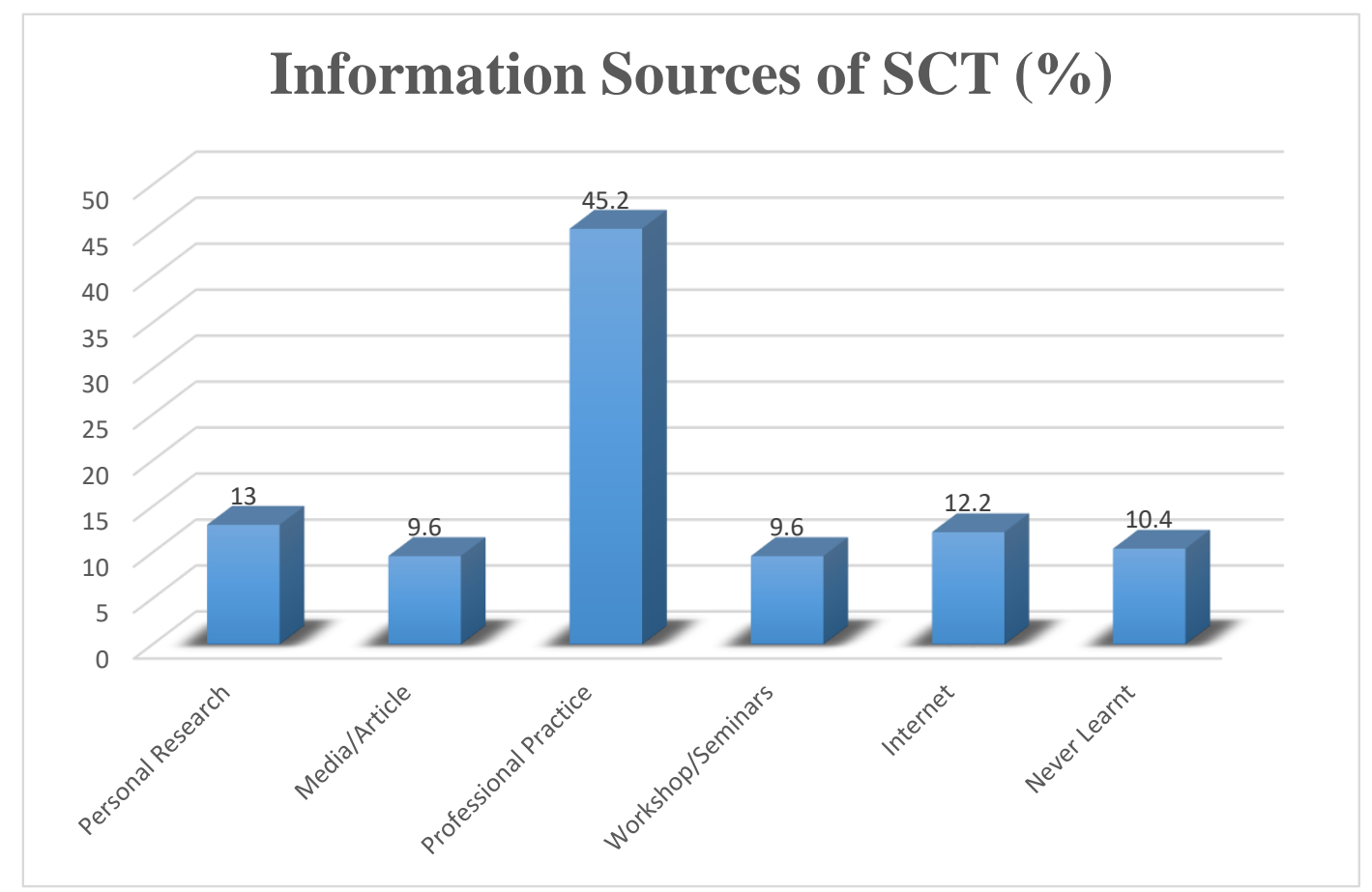

Figure 1. Information sources of the self-curing technique.

\subsubsection{Period of Time When SCT Was First Heard}

The result of the analysis presented in Figure 2 reveals five-timeline scales by which SCT came across to the respondents. These timelines are: $6.1 \%$ in the last month, which was followed by $15.7 \%$ in the last 12 months, $10.4 \%$ in the last three years. In addition, $47.8 \%$ heard about SCT more than three years ago while the remaining $20 \%$ of the respondents have not heard about self-curing concrete. This finding shows the need for proper awareness of the SCT method starting from undergraduate to post-graduate training studies and other construction related programs.

\section{When First You Heard About SCT (\%)}

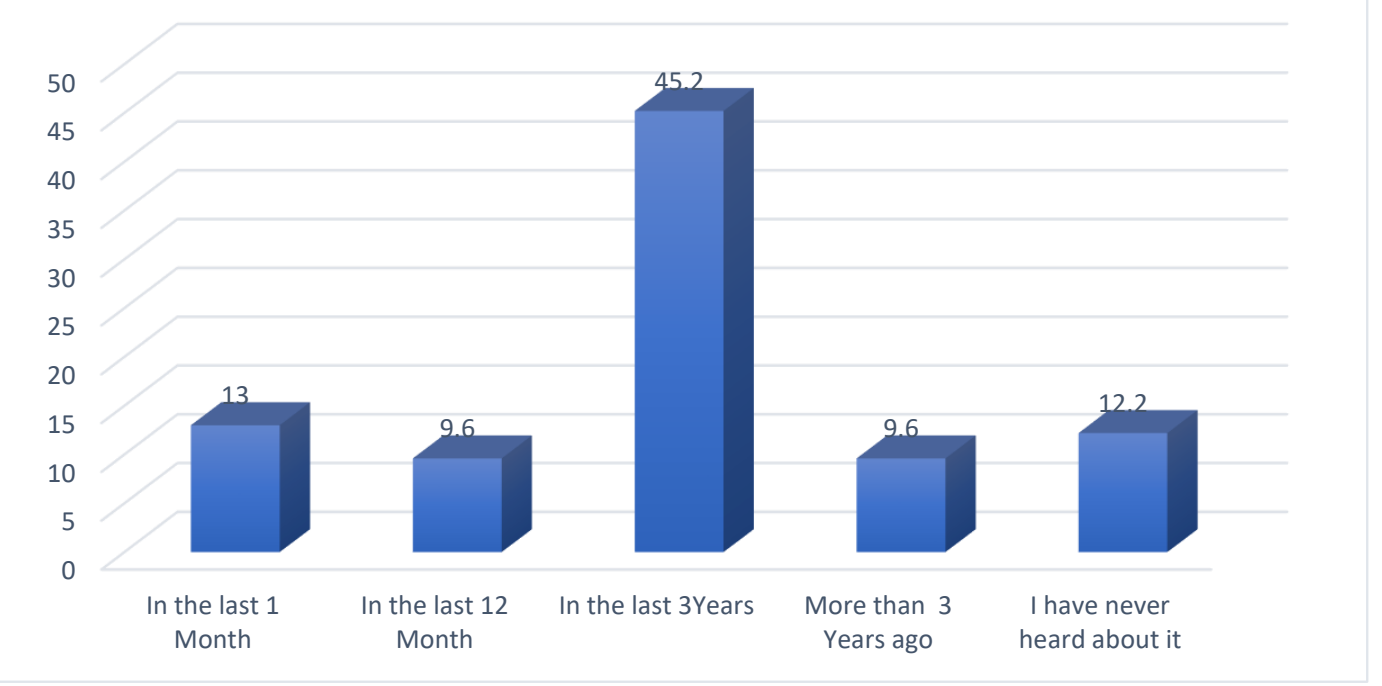

Figure 2. Period of time when SCT was first heard. 


\subsubsection{The Last Time SCT Technique Was Used}

The study investigated the last time SCT may have been used by respondents who have learned and heard about the self-curing technique. A total of $79 \%$ of the respondents indicated their percentage contribution of each timeline to the usage of the self-curing technique based on their experience. The result of the analysis presented in Figure 3 shows that $19.8 \%$ have used the SCT technique in the last month, $8.8 \%$ in the last six months, $14.3 \%$ have used it in the last 12 months, $23.1 \%$ have used it more than 12 months ago, and the majority $34.1 \%$ have never used an internal curing technique in their professional practice. The implication of these results is that most indigenous firms where builders and civil engineers are practicing in Lagos and may have not been involved in the construction of high rise buildings and heavy civil engineering works where SCT is practiced.

\section{LAST TIME SCT WAS USED BY RESPONDENTS (\%)}

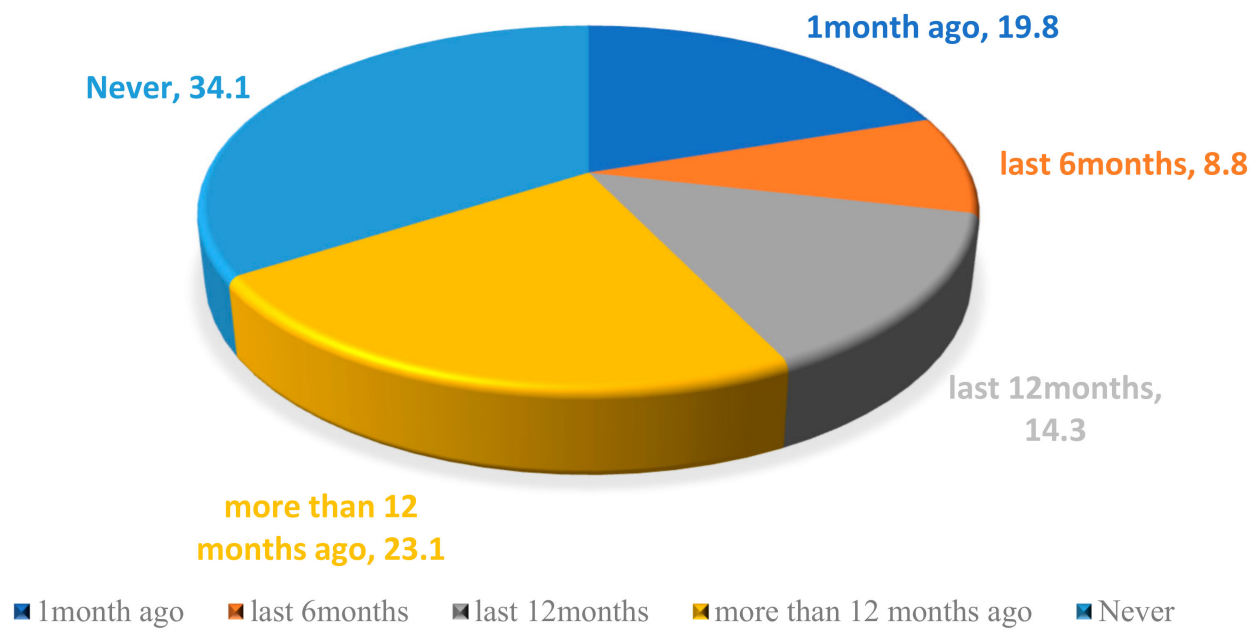

Figure 3. Last time the SCT technique was used.

\subsubsection{Perceived Effectiveness of SCT in Providing Internal Water}

The perceived effectiveness of the SCT technique in providing internal water is sought from $66 \%$ of those who have used it at various times, which is presented in Figure 4 . As shown, $55.0 \%$ perceived that SCT is extremely effective in providing internal water for further hydration of cement paste, $28.3 \%$ held the opinion of a "very effective" option, $7.7 \%$ held a somewhat effective opinion, $1.7 \%$ held a not so effective perception, $6.7 \%$ held a much less effective view, and $1.7 \%$ had no idea of the effectiveness of SCT in providing internal water necessary for hydration of cement paste. This result shows an increased effectiveness of SCT in providing internal water in HPC by builders and civil engineers. 


\section{EFFECTIVENESS OF SCT IN PROVIDING INTERNAL CURING (\%)}

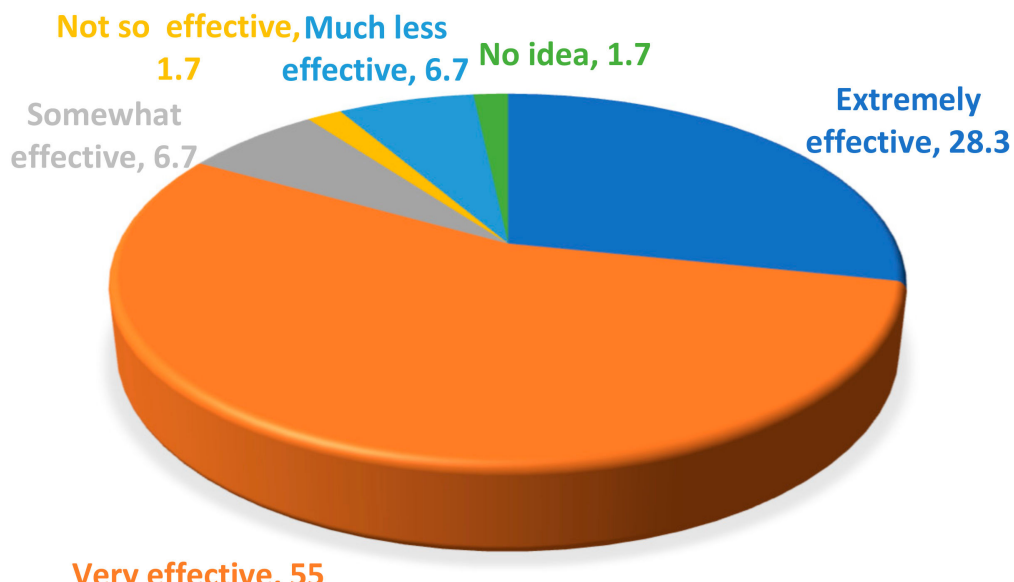

Figure 4. Perceived effectiveness of SC in providing internal water.

\subsubsection{Likelihood of Specifying and Implementing SC in HPC}

Figure 5 shows that $53.3 \%$ out of $98.3 \%$ of respondents who held the view that SCT is adequate in providing internal water are more likely to specify and implement SCT in HPC, which was followed by a much more likely scale option of $28.3 \%$. Those that are likely and less likely to specify are within $10.0 \%$ and $6.7 \%$, respectively, while only $1.7 \%$ showed no likelihood in specifying and implementing $\mathrm{SC}$ in high performance concrete. This shows a promising interest in SCT in high performance concrete when stakeholders are exposed to the benefits.

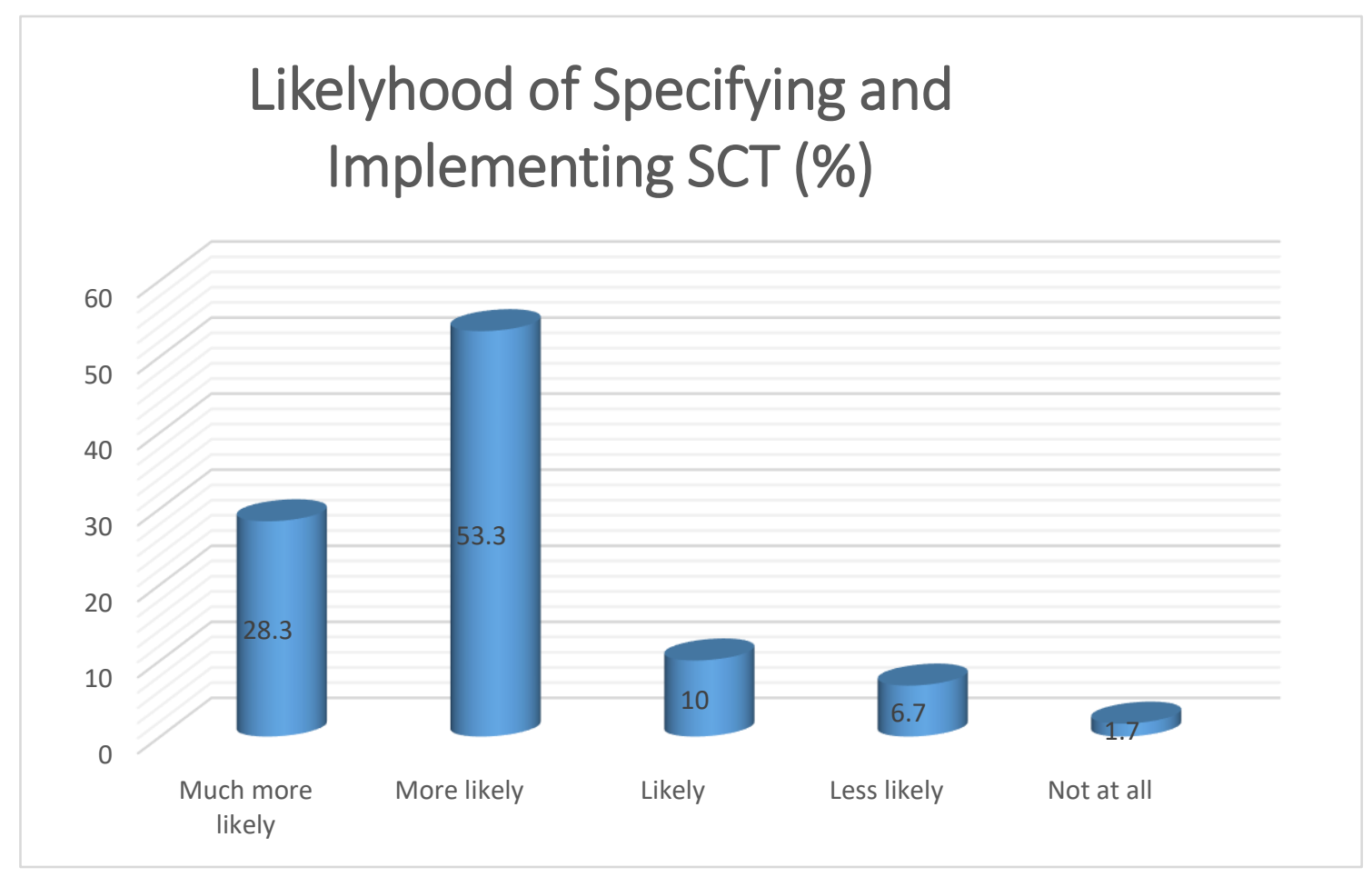

Figure 5. The likelihood of specifying and implementing SCT. 


\subsubsection{Curing Methods That Are Likely to Be Adopted}

The study sought to know the curing methods from $66 \%$ of respondents who have used SCT at various times in high performance concrete. The respondents were to indicate the percentage contribution of each of the curing practices based on their experience. The result of the analysis is presented in Figure 6. The result in Figure 6 shows the frequency and percentage contribution of the curing methods available in concrete. The results reveal that $25.0 \%$ held that curing by immersion and sprinkling/spraying will provide the required properties in HPC, respectively, while $27.7 \%$ held that curing by covering with the burlap sack/membrane provide effective curing in HPC. Additionally, $15.0 \%$ perceived that self-curing is the appropriate method applicable to HPC while $8.3 \%$ held that none of the methods can be used in mitigating autogenous shrinkage in HPC. These results show that the concept of self-curing may still be a confusing practice among builders and civil engineers in Nigeria.

\section{Curing Practices Likely to Adopt (\%)}

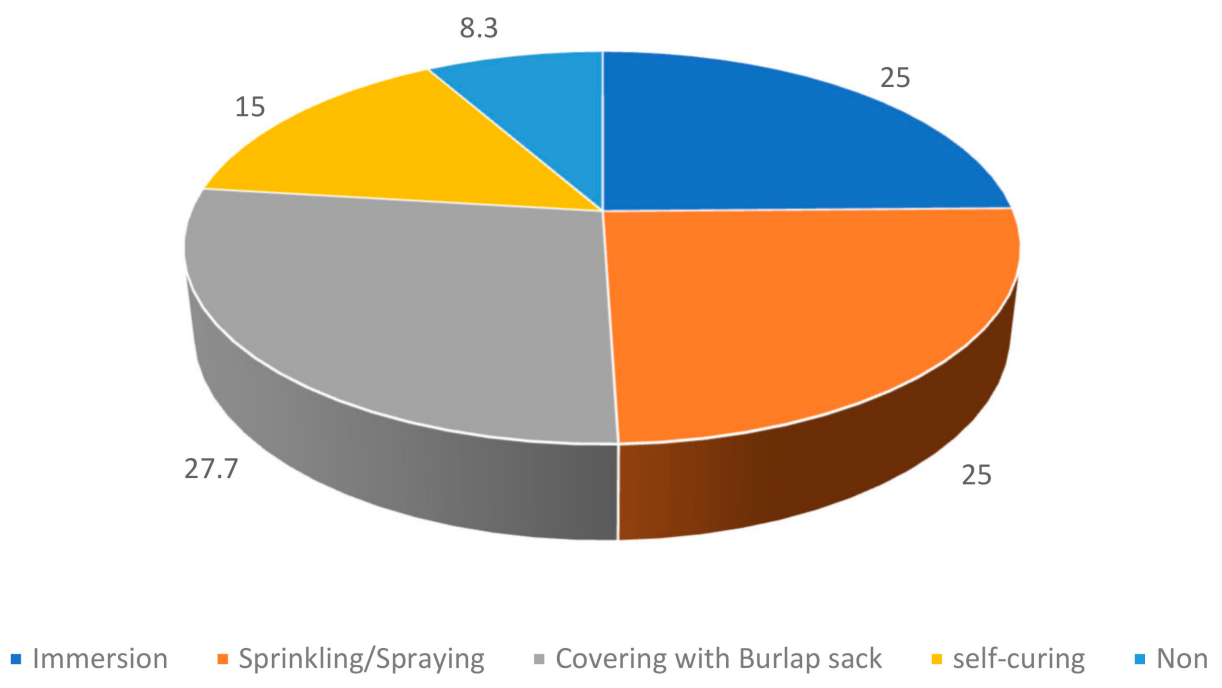

Figure 6. Curing practices likely to adopt in HPC.

\subsubsection{Perceived Benefits Derived from a Self-Curing Technique}

The study sought to know the most beneficial factors contributing to the implementation of internal curing as shown in Table 2 . The $66 \%$ of respondents who have used and knew the effectiveness of SCT were required to rate the identified factors in the order of their level of benefits derived from implementing HPC by responding on a 5-point Likert scale ranging from 1-5 (1 = "not beneficial", 2 = "slightly beneficial", 3 = "moderately beneficial", 4 = "beneficial", $5=$ "highly beneficial"). The results reveal that, out of 10 of the most identified benefits investigated, Lower permeability to water top the list of the perceived benefits of the self-curing method in HPC with a mean score of 2.45. This was followed by a reduced coefficient of thermal expansion with a mean score of 2.43 , improved microstructure of the cementious paste with a mean score of 2.38 and a reduced moisture evaporation with a mean score of 2.32, higher stiffness and a reduced creep with a mean score of 2.25, and an improved interfacial transition zone with a mean score of 2.20. The results also reveal beneficial factors that are perceived to have lower gains. These are increased cement hydration with a mean score of 2.02 , satisfactory impact to resistance with a mean score of 2.00, reduced autogenous shrinkage and cracking with a mean score of 1.95 , and increased strength and durability with a mean score of 1.93 . The findings are at variance with experimental studies from References [12,24,25]. These studies reveal reduced autogenous shrinkage, crack-free microstructure, and increased durability of the concrete 
product as the major enablers of self-curing technology. The implication of these results on the study respondent lies in their inability to understand the concept, usefulness, and application of internal curing in high performance concrete.

Table 2. Benefits derived from self-curing techniques in construction projects.

\begin{tabular}{clccc}
\hline S/N & \multicolumn{1}{c}{ Benefits } & Mean & Std. Deviation & Rank \\
\hline 1 & Lower permeability & 2.45 & 1.032 & 1 \\
2 & Reduced coefficient of thermal expansion & 2.43 & 1.095 & 2 \\
3 & Improved microstructure of the cementious paste & 2.38 & 1.075 & 3 \\
4 & Reduced moisture evaporation & 2.32 & 1.200 & 4 \\
5 & Higher stiffness and reduced creep & 2.25 & 1.202 & 5 \\
6 & Improved interfacial transition zone & 2.20 & 1.086 & 6 \\
7 & Increased cement hydration & 2.02 & 1.112 & 7 \\
8 & Satisfactory impact resistance & 2.00 & 1.042 & 8 \\
9 & Reduced autogenous shrinkage and cracking & 1.95 & 0.964 & 9 \\
10 & Increased strength and durability & 1.93 & 0.972 & 10 \\
\hline
\end{tabular}

\section{Conclusions}

It has been established from research studies that a self-curing mechanism provides the required water reservoir necessary to accomplish a hydration process in low water to binder concrete. To increase the performance of HPC in construction projects, stakeholders' awareness and benefits of SCT in mitigating autogenous shrinkage remains paramount. It is generally believed that concrete that is not adequately cured may lead to cracks or a total collapse. This means that any attempt towards providing insight into a shift in traditional curing will ultimately affect the construction sector. Therefore, this study investigated the awareness and benefits of SCT in high performance among builders and civil engineers.

A cross-sectional survey research design was adopted for the study. Questionnaires were used as the major instrument for collecting the primary data from the respondents. Total samples of two hundred and fifty (250) respondents were drawn from the monthly meeting register of members of the Nigeria Institute of Building (NIOB) and the Nigeria Society of Engineers (NSE) (Civil Engineers) Lagos State chapters. The results indicate that about $21 \%$ of selected builders and civil engineers practicing in Lagos are not aware and familiar with the concept of self-curing technology while about $43.1 \%$ of respondents who have knowledge of SCT have never used it in their professional practice. It further reveals that most indigenous contracting firms where builders and civil engineers are practicing may not have been involved in the construction of high rise buildings and heavy civil engineering works where SCT can be practiced. The study further establishes that lower permeability, reduced coefficient of thermal expansion, and improved microstructure of cementitious paste are perceived as top benefits warranting the adoption of a self-curing method in HPC. The implication of this study to construction professionals in Nigeria is in developing a capacity in the innovation practices in high-strength concrete technologies that will make them strike a balance with international counterparts. The findings of the study provide strong evidence that all the benefits derived from literature are relevant in pursuing SCT.

\section{Limitation of Study}

This study is considered as a subjective assessment where a survey research design was adopted in assessing builders and civil engineers' perceptions on the awareness and benefits of self-curing concrete. Further studies should adopt a case study approach where in-depth knowledge of a self-curing concrete technique will be established. Additionally, further studies on the benefits of self-curing that will focus on only those engaged in the construction of heavy civil engineering facilities and high-rise buildings is recommended. 
Author Contributions: The authors in this paper collaborated effectively to the development and final copy of the article. D.O.N conceived the idea and wrote the paper, J.O.A. and O.J. supervised and validated the research instrument while R.O. performed data collection and analyses.

Funding: The authors acknowledged the financial support of Covenant University Center for Research and Innovation Development (CUCRID) in publishing the article.

Conflicts of Interest: The authors declare no conflict of interest.

\section{References}

1. Orosz, K. Early Age Autogenous Deformation and Cracking of Cementitious Materials-Implications on Strengthening of Concrete. Ph.D. Dissertation, Luleå Tekniska Universitet, Luleå, Sweden, 2017.

2. Olawuyi, B.J. The Mechanical Behaviour of High-Performance Concrete with Superabsorbent Polymers (SAP). Ph.D. Dissertation, University of Stellenbosch, Stellenbosch, South Africa, 2016.

3. Kovler, K.; Jensen, O.M. Novel techniques for Concrete Curing: New Method for Low w/cm Mixtures. Concr. Int. 2005, 27, 39-42.

4. Bashandy, A.A.; Soliman, N.M.; Elrahman, M.H. Recycled Aggregate Self-curing High-strength Concrete. Civ. Eng. J. 2017, 3, 427-441.

5. Mousa, M.I.; Mandy, M.G.; Adbel-Raheem, H.; Yehia, A.Z.Y. Self-curing concrete types; water retention and durability. Alex. Eng. J. 2015, 54, 565-575. [CrossRef]

6. Di Bella, C.; Villani, C.; Phares, N.; Hausheer, E.; Weiss, J. Chloride transport and service life in internally cured concrete. In Structures Congress; American Society of Civil Engineers: Reston, VA, USA, 2012; pp. 686-698.

7. El-Dieb, A.S. Self-curing concrete: Water retention, hydration and moisture transport. Constr. Build. Mater. 2007, 21, 1282-1287. [CrossRef]

8. Justs, D.; Wyrzykowski, M.; Bajare, D.; Laura, P. Internal curing by superabsorbent polymers in ultra-high-performance concrete. Cem. Concr. Res. 2015, 76, 82-90. [CrossRef]

9. Madduru, S.R.I.; Pallapotha, S.N.R.; Pancharathi, R.K.; Garja, R.K.; Chakilam, R. Effect of self-curing chemicals in self-compacting mortars. Constr. Build. Mater. 2016, 107, 356-364.

10. Krishna, J.B.; Jaipal, R. Comparative and experimental study on self-curing concrete. Int. J. Res. Sci. Adv. Eng. 2017, 2, 118-129.

11. Pytllick, D.; Blick, V. Two Options of Self-Curing of High Performance Concrete. Solid State Phenom. 2018, 272, 88-93. [CrossRef]

12. Gopala, K.V.S.; Putturu, M.K. Self-curing concrete with different self-curing agents. IOP Conf. Ser. Mater. Sci. Eng. 2018, 330, 012120. [CrossRef]

13. Udhanyan, R.; Rajamane, N.P. Experimental study of self-compacting self-curing concrete. Int. J. Civ. Eng. Technol. 2017, 8, 638-643.

14. Olawuyi, B.J.; Boshoff, W.P. Influence of SAP content and curing a on air void distribution of high performance concrete using 3D volume analysis. Constr. Build. Mater. 2017, 135, 580-589. [CrossRef]

15. Youssef, D. The Use of Lightweight Sand for Internal Curing and Its Effect on Performance of HPC Used for Concrete Infrastructures. Ph.D. Dissertation, Université de Sherbrooke, Sherbrooke, QC, Canada, 2013.

16. Afifi, M.S. Internal Curing of High Performance Concrete Using Lightweight Aggregate and Recycled Aggregate. Master's Thesis, The American University in Cairo, New Cairo, Egypt, 2016.

17. Rahman, S. Investigation of Concrete Properties with Brick Chips as Internal Curing Medium. Master's Thesis, Bangladesh University of Engineering and Technology, Dhaka, Bangladesh, 2016.

18. Akinwumi, I.I.; Gbadamosi, Z.O. Effects of curing condition and curing period on the compressive strength development of plain concrete. Int. J. Civ. Environ. Res. 2014, 1, 83-99.

19. Abalaka, A.F.; Okoli, O.G. Effects of limited initial curing durations on mechanical properties of concrete. J. Civ. Eng. Constr. Technol. 2013, 4, 104-109.

20. Olanade, K.A.; Fitriani, H.; Kola, O.T. Regression models for compressive strength of concrete under different curing conditions. MATEC Web Conf. 2017, 101, 05013. [CrossRef]

21. Bentz, D.P.; Weiss, W.J. Internal Curing: A 2010 State-of-the-Art Review; US Department of Commerce, National Institute of Standards and Technology: Gaithersburg, MD, USA, 2011. 
22. Henkensiefken, R. Internal Curing in Cementitious Systems Made with Saturated Lightweight Aggregate. Ph.D. Dissertation, Purdue University, West Lafayette, IN, USA, 2008.

23. Revalty, V.; Lakashimi, C.J. Experimental study on self-curing concrete with fly ash and quarry dust. Int. J. Civ. Eng. Spec. Issue 2017, 180-183.

24. Mehdipour, I.; Khayat, K.H. Enhancing the performance of calcium sulfoaluminate blended cements with shrinkage reducing admixture or lightweight sand. Cem. Concr. Compos. 2018, 87, 29-43. [CrossRef]

25. Shen, D.; Jiang, J.; Zhang, M.; Yao, P.; Jiang, G. Tensile creep and cracking potential of high performance concrete internally cured with super absorbent polymers at early age. Constr. Build. Mater. 2018, 165, 451-461. [CrossRef]

26. Kang, S.; Hong, S.; Moon, J. Shrinkage characteristics of heat-treated ultra-high-performance concrete and its mitigation using superabsorbent polymer based internal curing method. Cem. Concr. Compos. 2018, 89, 130-138. [CrossRef]

27. Mousa, M.I.; Mandy, M.G.; Adbel-Raheem, H.; Yehia, A.Z.Y. Physical properties of self-curing concrete (SCUC). HBRC J. 2015, 11, 167-175. [CrossRef]

28. Kamal, M.M.; Safan, M.A.; Bashandy, A.A.; Khahil, A.M. Experimental investigation of the behavior of normal strength and high strength self-curing self-compacting concrete. J. Build. Eng. 2018, 16, 79-93. [CrossRef]

29. Wyrzykowski, M.; Lura, P. Controlling coefficient of thermal expansion of cementitious material-A new application of superabsorbent polymers. Cem. Concr. Compos. 2013, 35, 49-58. [CrossRef]

30. Zeng, Q.; Li, K.; Feng-Chong, T.; Dangla, P. Effects of porosity on the thermal expansion coefficient of cement paste and mortars. Constr. Build. Mater. 2012, 28, 468-475. [CrossRef]

31. Zhang, J.; Sun, H.; Wan, J.; Yi, Z. Study on microstructure and mechanical property of interfacial transition zone between limestone aggregate and Sialite paste. Constr. Build. Mater. 2009, 23, 3393-3397. [CrossRef]

32. Sun, X.; Zhang, B.; Dai, Q.; Yu, X. Investigation of internal curing effects on microstructure and permeability of interface transition zones in cement mortar with SEM imaging, transport simulation and hydration modeling techniques. Constr. Build. Mater. 2015, 1, 366-379. [CrossRef]

33. Nie, S.; Hu, S.; Wang, F.; Yaun, P.; Zhu, Y.; Ye, J.; Liu, Y. Internal curing-a suitable method for improving the performance of heat cured concrete. Concr. Build. Mater. 2016, 122, 294-301. [CrossRef]

34. Ridi, F.; Fratini, E.; Baglioni, P. Cement: A two thousand year old nano-colloid. J. Colloid Interface Sci. 2011, 357, 255-264. [CrossRef] [PubMed]

35. Kim, H.K.; Lee, H.K. Hydration kinetics of high-strength concrete with untreated coal bottom ash for internal curing. Cem. Concr. Compos. 2018, 91, 67-75. [CrossRef]

36. Kevern, J.T.; Nowasell, Q.C. Internal curing of pervious concrete using lightweight aggregates. Constr. Build. Mater. 2018, 161, 229-235. [CrossRef]

37. Olawuyi, B.J.; Boshoff, W.P. Compressive strength of high-performance concrete with absorption capacity of super-absorbing polymer (SAP). In Proceedings of the Research and Application in Structural Engineering, Mechanics and Computation, Cape Town, South Africa, 2-4 September 2013; Zingoni, Ed.; Taylor \& Francis Group: London, UK, 2013; pp. 1679-1683.

38. Pickle, D.; Tighe, S.; West, J.S. Assessing benefits of pre-soaked recycled concrete aggregate on variably cured concrete. Constr. Build. Mater. 2017, 141, 245-252. [CrossRef]

39. Zang, J.; Wang, J.; Han, Y. Simulation of moisture field of concrete with pre-soaked light weight aggregate addition. Constr. Build. Mater. 2015, 96, 599-614. [CrossRef]

40. Di Bella, C.; Griffa, M.; Ulrich, T.J.; Lura, P. Early-age elastic properties of cement-based materials as a function of decreasing moisture content. Cem. Concr. Res. 2016, 89, 87-96. [CrossRef]

41. Maruyama, I.; Teramoto, A. Effects of water-restraining lightweight aggregate on the reduction of thermal expansion coefficient in mortar subject to temperature histories. Cem. Concr. Compos. 2012, 34, 1124-1129. [CrossRef] 
42. Kothari, C.R. Research Methodology: Methods and Techniques, 2nd ed.; New Age International: New Delhi, India, 2004.

43. Williams, C. Research Methods. J. Bus. Econ. Res. 2007, 5, 65-72. [CrossRef] 